\begin{tabular}{l} 
Sharif University of Technology \\
Scientia Iranica \\
SCIENTIA \\
IRAN \\
Thanstions A: Civil Engineering \\
\hline
\end{tabular}

\title{
Volume change behavior of stabilized expansive clay with lignosulfonate
}

\author{
R. Noorzad* and B. Ta'negonbadi \\ Faculty of Civil Engineering, Babol Noshirvani University of Technology, Babol, Iran.
}

Received 7 January 2018; received in revised form 23 May 2018; accepted 6 August 2018

\section{KEYWORDS}

Lignosulfonate; Stabilization;

Expansive clay;

Swelling properties;

Consolidation

properties;

Wet and dry cycles.

\begin{abstract}
This paper presents the swelling and consolidation characteristics of lignosulfonate (LS) stabilized expansive clay. Expansive clay samples of Amol city in Iran have been used in this research. Based on Atterberg limits and unconfined compressive strength tests, the optimum percentage of LS for the treatment of this clay was determined at $0.75 \%$ by soil dry weight. To investigate the swelling and consolidation properties of untreated and LS-treated remolded samples, one-dimensional swell and consolidation tests were conducted on these samples. Test results showed that LS had considerable effect on the consolidation and swelling behavior of the expansive clay. Moreover, the effects of compaction water content change and cyclic wetting and drying on the volume change properties of unstabilized and LS-stabilized samples were investigated. Untreated and LS-treated specimens showed different consolidation behaviors towards the variations of compaction moisture content due to the alteration of soil expansivity category from high to moderate. The Scanning Electron Microscope (SEM) images of samples showed that the soil specific area was reduced because of stabilization. This reduction in soil specific area led to the decrease of affinity of samples to moisture increase; thus, the volume change of expansive clay decreased.

(C) 2020 Sharif University of Technology. All rights reserved.
\end{abstract}

\section{Introduction}

High volume change and low shear strength of fine soils, especially expansive soils, in buildings and embankment construction pose many problems for geotechnical and civil engineers. Changes in moisture content upon periodical variations in the surrounding conditions or dummy factors change the mechanical characteristics of these soils. Minerals that exist in expansive soil make it able to absorb water. When expansive soil absorbs water, its volume increases [1]. During high-water

*. Corresponding author. Tel: +98 113527837r

E-mail addresses: rn0864@gmail.comand

rnoorzad@nit.ac.ir (R. Noorzad);

bahram.gonbadi@gmail.com (B.Ta'negonbadi) content seasons, infrastructure soil, which is expansive, will swell and lead to the lifting of a structure or other buildings. Conversely, with a decrease in soil water content, expansive soil collapses and leads to building settlement [2]. However, consequential damages of this soil can be extensive. Numerous pieces of research have been performed to address the damages of expansive soil to road infrastructure and light buildings [3$6]$. The application of expansive soil in its natural condition during project construction is the main cause of such damages. Expansive soil compaction in a dry state becomes very hard. When it becomes wet, it gets extremely sticky [7]. The applicability of such soil can be enhanced by soil stabilization to improve its geotechnical properties. Among the soil treatment methods, chemical stabilization is a valuable and effective method to improve the volume change behavior and shear strength of the soil. A 
number of researchers have studied the geotechnical characteristics of stabilized expansive soil and other problematic soils after the addition of traditional stabilizers such as cement, gypsum, lime, and fly ash [2-3,813]. However, these traditional stabilizers can harm the environment. Such treatment can increase the soil $\mathrm{pH}$, which may affect plant growth and the quality of groundwater. Moreover, a high $\mathrm{pH}$ can corrode buried utilities $[14,15]$.

A by-product of industry called lignosulfonate (LS) is a widely used valuable soil stabilizer [14-20]. This chemical additive is lignin based and increases soil durability. Additionally, its use does not harm the environment [15]. Because a large amount of this agent is produced worldwide as a by-product, it is relatively inexpensive. The comparison of traditional stabilizers and LS shows that LS is non-toxic and its use for soil stabilization does not change the $\mathrm{pH}$ of the soil [17].

The enhanced performance of the LS-treated soil is related to a decrease in the double-layer thickness upon the neutralization of the negative surface charge of the clay particles and the consequent formation of steady aggregation [21]. Alazigha et al. [14] investigated the possible effects of LS when stabilizing expansive clay by performing swelling tests. Their results showed that the optimum content of LS to attain an appropriate enhancement in the swelling percentage was $2 \%$ of the dry soil weight [14]. While completing their previous work, Alazigha et al. [22] examined the stabilization mechanism of the expansive clay with LS. Their results indicated that the swelling percent was intimately related to the amount of water adsorbed by the expansive clay minerals. Moreover, they found that the adsorption of LS on the mineral surfaces provided waterproofing effect on soil due to the hydrophobic nature of LS, which in turn contributed to a decrease in the extent of swelling of the otherwise expansive soil [22]. Ta'negonbadi and Noorzad [23] conducted a series of Unconfined Compressive Strength (UCS) tests to study the shear strength and durability of LS-stabilized high plasticity clay. They found that the stabilization with LS improved the soil durability and, also, increased the stiffness and UCS of the soil without leading to considerable brittle behavior. The optimum content of LS used to stabilize high plasticity clay was $0.75 \%$ by soil dry weight [23].

Many researchers have studied LS-treated soil and focused on sandy silt, silty clay, and low plasticity clay [15-21]. As stated earlier, few researchers have investigated expansive clay so far $[14,22,23]$. The goal of the current study is to evaluate the influence of LS on the swelling and consolidation properties of the expansive clay. In addition, the effects of compaction moisture content change, density change, and cyclic wetting and drying on the volume change behavior of the untreated and LS-treated expansive clay were investigated. To interpret and confirm the test results, Scanning Electron Microscope (SEM) micrographs were taken of the untreated and LS-treated samples.

\section{Laboratory investigation}

Testing was carried out by mixing different contents of this agent (by dry weight of soil) with the soil to investigate the effect of LS on the volume change of expansive clay. Testing for measuring the Atterberg limits, UCS, and one-dimensional swell and consolidation was conducted on the untreated and LS-treated soil.

According to the standard proctor compaction test method, ASTM D-698 [24], for each dosage of LS, Optimum Moisture Content (OMC) and Maximum Dry Unit Weight (MDUW) of soil-LS mixtures were determined so that they could be used in the stabilized samples. In the beginning, according to the studies performed on different LS-stabilized soils [14-18], the usual contents $(0.5,1,2,3$, and 4$)$ of this agent for the stabilization of the soil were determined. Then, the optimum content of LS was selected based on the results of Atterberg limits, UCS, and the ASTM D-4609 [25] proposal. Given that the application of UCS test is quite convenient, available, and inexpensive and based on researchers' experience in this regard [16,26,27], It is applied to select appropriate curing time for stabilized samples. In one-dimensional swell and consolidation tests, this optimum content of LS and appropriate curing time were used to prepare the treated specimens. To prepare treated specimen with $95 \%$ MDUW, in performing the UCS tests according to ASTM D2166 [28], at first, different dosages of LS by soil dry weight were mixed with a specified amount of water to attain OMC; then, this mixture was added to the soil with a predetermined weight. Instantly after the preparation of a homogenous blend of soil and waterLS mixture, the resulting mixture was compacted into a metal mold (50 $\mathrm{mm}$ in diameter and $100 \mathrm{~mm}$ in height) under static compaction in five layers [29]. After the compaction of each layer, the layer surface was scarified by about $3 \mathrm{~mm}$ to ensure the uniformity of the sample. The method described above is consistent with the methods used by Chen and Indraratna [15] and Pourakbar et al. [30]. The prepared samples were then sealed using a double-layer plastic wrap and kept in a room at a controlled temperature in different curing time durations $(0,4,7,14,28$, and 35 days $)$. To ensure the homogeneity of the sample and the uniformity of the density with respect to the total height of the sample, several prepared samples were divided using a narrow saw into six to eight parts. Then, the weight and volume of each part were measured. Finally, the density of each part was calculated, and it was observed that the difference in the density of different 
parts of the sample from the target density was not considerable. Therefore, the prepared samples were considered as homogeneous samples.

To examine the swelling characteristics of untreated and LS-treated samples, free swelling tests were conducted on the samples based on ASTM D-4546 [31]. Free swelling test specimen was remolded uniformly under static compaction in three layers $(50 \mathrm{~mm}$ in diameter and $20 \mathrm{~mm}$ in height) similar to the previously described method for the UCS test sample preparation and based on ASTM D-4546 [31] proposal.

Consolidation properties of untreated and LStreated specimens were determined using a onedimensional consolidation apparatus based on ASTM D-2435 [32]. The test samples were prepared exactly similar to the swelling test specimens. In both swelling and consolidation tests, the effects of changes in density (90\% and $95 \%$ MDUW), compaction moisture content (optimum and optimum $\pm 2 \%$ ), and wetting and drying cycles on the volume change of the soil were evaluated. Similar to the work done by Al-Homoud et al. [33], wetting and drying cycles were conducted using a consolidation ring within the consolidation apparatus. For wetting the samples in these experiments, the consolidation chamber was filled with water and kept in this condition for $24 \mathrm{~h}$ to achieve the end of primary swell [33]. In the drying stage, the water in the consolidation chamber was discharged, and after bringing out the consolidation ring and picking out the porous stones and paper filters, the specimen was air dried under laboratory conditions for almost $24 \mathrm{~h}$ to its initial moisture content. The specimens were subjected to one, two, three, and four cycles of wetting and drying.

\section{Materials}

\subsection{Clay}

The clay soil used was collected from the city of Amol, Iran. The gradation of the Amol clay based on ASTM D-422 [34] is shown in Figure 1.

Atterberg limits test results indicate that Liquid Limit (LL) and Plastic Limit (PL) of the Amol clay were approximately $55 \%$ and $26 \%$, respectively. The Plasticity Index (PI) of this clay was determined to be approximately $29 \%$. The free swelling of this clay was approximately $2.6 \%$ at $\mathrm{OMC}$ and $95 \% \mathrm{MDUW}$. In accordance with ASTM D-2487 [35], this clay was categorized as high plasticity $(\mathrm{CH})$ and could be classified as expansive. The high PI of $29 \%$ puts the clay in the group of 'highly' expansive soil using the classifications introduced by Chen [4] (i.e., PI $=20-55 \%$ ) and Holtz and Gibbs [36] (i.e., PI $=23-45 \%$ ). The results of compaction tests disclosed that the OMC and MDUW of the clay were equal to $21.3 \%$ and $16.3 \mathrm{kN} / \mathrm{m}^{3}$, respectively. The specific gravity according to ASTM

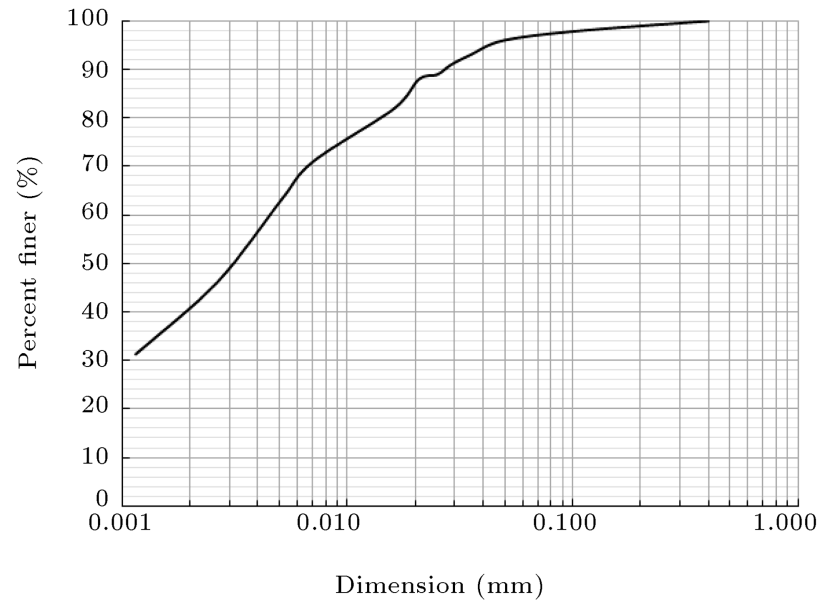

Figure 1. Gradation of the studied clay.

Table 1. Chemical composition of clay and lignosulfonate.

\begin{tabular}{ccc}
\hline \multirow{2}{*}{$\begin{array}{c}\text { Chemical } \\
\text { composition }\end{array}$} & \multicolumn{2}{c}{ By total weight (\%) } \\
\cline { 2 - 3 } & Clay (CH) & Lignosulfonate \\
\hline $\mathrm{SiO}_{2}$ & 55.57 & 0.18 \\
$\mathrm{Al}_{2} \mathrm{O}_{3}$ & 18.80 & 0.11 \\
$\mathrm{MgO}$ & 2.85 & 0.66 \\
$\mathrm{Na}_{2} \mathrm{O}$ & 1.55 & 0.13 \\
$\mathrm{TiO}_{2}$ & 0.72 & - \\
$\mathrm{CaO}$ & 3.38 & 7.39 \\
$\mathrm{~K}_{2} \mathrm{O}$ & 2.91 & 0.12 \\
$\mathrm{P}_{2} \mathrm{O}_{5}$ & 0.29 & - \\
$\mathrm{Fe}_{2} \mathrm{O}_{3}$ & 6.97 & 0.05 \\
$\mathrm{MnO}$ & 0.16 & - \\
L.O.I & 6.8 & 88.18 \\
$\mathrm{~F}^{* *}$ & - & 0.19 \\
$\mathrm{~S}^{* * *}$ & - & 2.99 \\
\hline *Loss on ignition at $950^{\circ} \mathrm{C}$ for 90 minutes; \\
**Fluorine; & & \\
*** Sulfur. & &
\end{tabular}

D-854 [37] was 2.70. Table 1 shows the results of X-Ray Fluorescence testing employed to specify the chemical composition of the studied clay according to ASTM E1621 [38].

\subsection{Lignosulfonate ( $L S$ )}

LS used in this research is the by-product of wood and paper industries. It is a lignin-based polymer compound that contains a number of hydrophilic groups including sulfonate and phenolic hydroxyl and alcoholic hydroxyl and hydrophobic groups including the carbon chain [16]. The LS used in this study is a lightbrown powder soluble in water. Based on Fourier Transform Infrared (FTIR) spectroscopy conducted on this agent according to ASTM E-1252 [39] whose results and function groups are shown in Figure 2 and 
Table 2. Function groups of Lignosulfonate (LS) based on related wavenumbers obtained from Fourier Transform Infrared (FTIR) spectroscopy.

\begin{tabular}{llll}
\hline Wave number $\mathbf{( 1 / c m )}$ & \multicolumn{1}{c}{ Function group } & $\begin{array}{c}\text { Group frequency, } \\
\text { wave number } \mathbf{( 1 / c m )}\end{array}$ & Reference \\
\hline 3396 & $-\mathrm{OH}$ (hydroxyl group) & $3200-3500$ & Coates [40] \\
2925 & $\mathrm{CH}_{2}$ (methylene) & $2915-2935$ & Coates [40] \\
2849 & ${\mathrm{O}-\mathrm{CH}_{3} \text { (methoxy) }}_{10}$ & $2815-2850$ & Coates [40] \\
1599 & $\mathrm{C}=\mathrm{C}$ (aromatic ring) & $1580-1615$ & Coates [40] \\
1460,1514 & $\mathrm{C}=\mathrm{C}$ (aromatic ring) & $1450-1510$ & Coates [40] \\
1426 & $\mathrm{C}=\mathrm{C}$ (aromatic ring) & $1426,1515,1600$ & Boeriu et al. [41] \\
1330 & -CH (methyne) & $1330-1350$ & Coates [40] \\
1219 & $\mathrm{C}-\mathrm{O}$ (aromatic (phenol)) & $1212-1235$ & Hergert [42] \\
1118 & $\mathrm{SO}$ (sulfonate) & $1100-1200$ & Coates [40] \\
1041 & $\mathrm{C}-\mathrm{O}$ (alcohol, primary) & $1040-1060$ & Jacox [43] \\
654 & $\mathrm{C}-\mathrm{S}$ stretching & $600-700$ & Rao et al. [44] \\
\hline
\end{tabular}

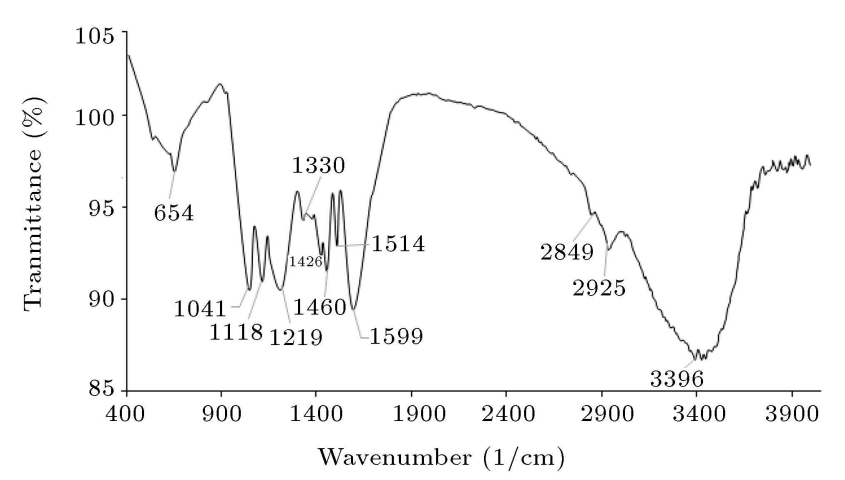

Figure 2. Fourier Transform Infrared (FTIR) spectroscopy of lignosulfonate.

Table 2, it is found that this material is LS based. The chemical composition of the used LS is shown in Table 1. Because the predominant salt in the LS is calcium, the LS used in this study is characterized as calcium LS.

\section{Results and discussions}

\subsection{Atterberg limits tests}

The results of the Atterberg limits tests on expansive clay mixed with different contents of LS are shown in Table 3 [23]. The PL of the clay did not change considerably with the addition of LS and remained almost constant, whereas the LL of the clay decreased significantly (from $55 \%$ to $39 \%$ ). This led to a considerable reduction (15\%) in the PI of the soil (from $29 \%$ to $14 \%$ ) at $0.75 \%$ LS addition [23]. However, an increase in LS beyond $0.75 \%$ adversely changed the soil characteristics. For example, at $4 \% \mathrm{LS}$, the LL decreased to $44 \%$ with a consequent decrease in PI to $18 \%$. This result is associated with the repulsive forces in the charged sections of the soil-LS mixture that did not contribute to stabilization [23]. The Atterberg limit test results indicate that the optimum LS content for treatment of Amol clay was $0.75 \%$ by soil dry weight. A decrease in the PI of the clay due to LS-treatment altered the category of the clay from highly expansive to moderate according to the classification developed by Chen [4] and Holtz and Gibbs [36].

Since the swelling and volume change behavior of the soil depends on the Atterberg limits and particularly PI [4,36], for this purpose, the Atterberg limits tests were used to select the optimum LS percentage. Moreover, the relationship between the PI and swelling behavior as mentioned in the study of Alazigha et al. [14] revealed that the optimum percentage obtained from PI and swelling test was the same for the stabilizing agent. As a result, in this research, the samples of swelling and consolidation tests were prepared using this obtained optimum content.

Table 3. Atterberg limits results of treated expansive clay [23].

\begin{tabular}{ccccc}
\hline Sample & $\begin{array}{c}\text { LS content } \\
(\mathbf{\%})\end{array}$ & $\begin{array}{c}\text { Liquid limit (LL) } \\
\mathbf{( \% )}\end{array}$ & $\begin{array}{c}\text { Plastic limit (PL) } \\
\mathbf{( \% )}\end{array}$ & $\begin{array}{c}\text { Plasticity index (PI) } \\
(\%)\end{array}$ \\
\hline Untreated & 0 & 55 & 26 & 29 \\
Treated & 0.75 & 39 & 25 & 14 \\
Treated & 2 & 41 & 26 & 15 \\
Treated & 3 & 43 & 26 & 17 \\
Treated & 4 & 44 & 26 & 18 \\
\hline
\end{tabular}


Table 4. Standard compaction test results of treated clay soil [23].

\begin{tabular}{cccc}
\hline Stabilizer & $\begin{array}{c}\text { Stabilizer } \\
\text { dosage }(\%)\end{array}$ & $\begin{array}{c}\text { Optimum moisture } \\
\text { content }(\%)\end{array}$ & $\begin{array}{c}\text { Maximum dry density } \\
\left(\mathbf{k N} / \mathbf{m}^{\mathbf{3}}\right)\end{array}$ \\
\hline None & - & 21.3 & 16.3 \\
LS & 0.5 & 21.4 & 16.2 \\
LS & 0.75 & 21.5 & 16.2 \\
LS & 1 & 21.6 & 16.1 \\
LS & 2 & 21.9 & 16.1 \\
LS & 3 & 22.1 & 16 \\
LS & 4 & 22.3 & 15.9 \\
\hline
\end{tabular}

\subsection{Compaction tests}

Table 4 shows the results of the compaction test for untreated and LS-treated expansive clays. The MDUW of the stabilized expansive soil decreased slightly, and the OMC increased slightly with an increase in LS content [23]. This reduction in the MDUW can be ascribed to decrease in LS specific gravity. The specific gravity $(G s)$ of the clay was 2.7 , and when this soil was mixed with $0.75 \%$ of LS with $G s=0.34$, then the Gs of the soil-LS mixture based on weighted averaging of the specific gravity of soil and LS was reduced to 2.67. With an easy calculation, it can be seen that this reduction of $\mathrm{Gs}$, which is also negligible, causes a slight decrease in the amount of MDUW. These performed computations confirm the results obtained from the compaction tests.

\subsection{Unconfined Compressive Strength (UCS) testing}

Figure 3 shows the relationships between the percentage rates of LS and UCS of the treated expansive soil versus curing time. The UCS of the treated clay increased significantly with an increase in curing time up to 28 days. After this time, the rate of

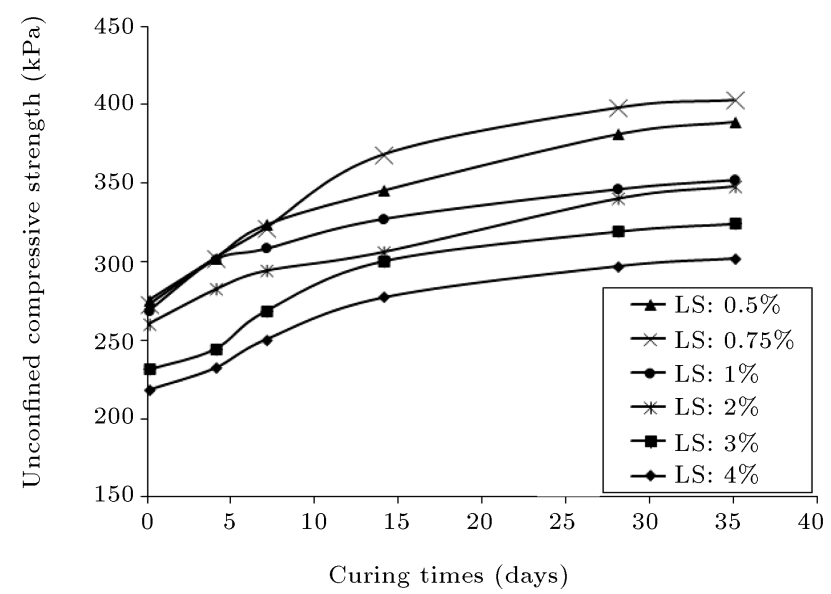

Figure 3. Relationship between the Unconfined Compressive Strength (UCS) and curing time for different percentage rates of lignosulfonate (LS). increase in the UCS of treated clay was found not significant; therefore, a 28-day curing time was chosen as appropriate for the treated samples. An increase in UCS caused by an increase in the curing time can be ascribed to the neutralization of negative charges on the surface of the clay minerals and a decrease in the mineral crystalline size caused by the creation of steady aggregation.

The maximum axial stress of expansive soil treated with different contents of LS at a curing time of 28 days is depicted in Figure 4. Increase in maximum axial stress with an increase in LS percentage from 0 to 0.75 was considerable; however, an increase in LS percentage beyond the $0.75 \%$ by soil dry weight decreased the maximum axial stress. The UCS test results indicate that the optimum LS content for stabilizing the expansive soil, as obtained from the results of Atterberg limits test, was $0.75 \%$ of the soil dry weight. Therefore, $0.75 \%$ was used as the optimum content of LS to prepare the stabilized specimens for the swelling and consolidation tests. A decrease in maximum axial stress with an increase in LS content beyond the optimum percentage relates to the repulsive forces created by additional polymer chains in the charged parts of the clay-LS admixture [23].

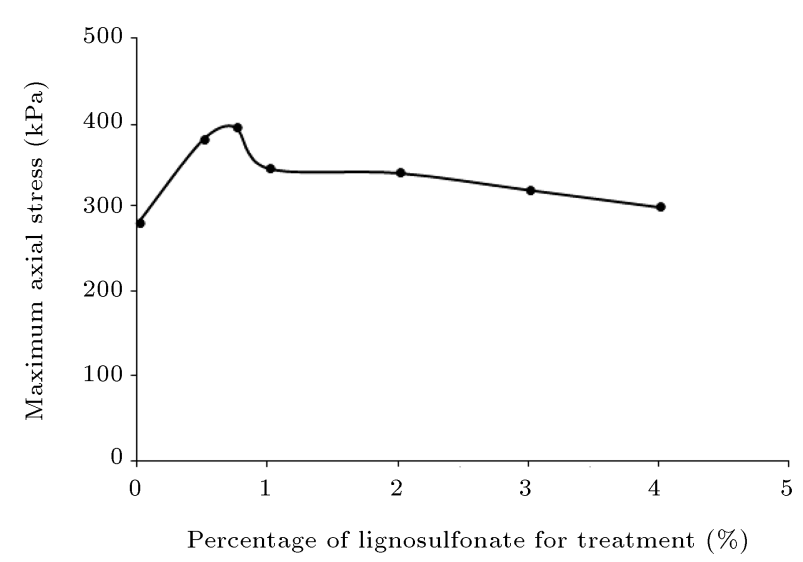

Figure 4. Maximum axial stress of the treated soil with different percentage rates of lignosulfonate (LS) for 28 days. 


\subsection{Swelling behavior}

Figure 5 shows the effect of LS-stabilization on the swelling percentage and swelling pressure of the expansive soil. When the clay sample (at OMC and $0.95 \mathrm{MDUW}$ ) was treated with $0.75 \% \mathrm{LS}$, the swelling percentage decreased from $2.59 \%$ to $1.73 \%$, which is a remarkable improvement in swelling behavior of the expansive soil. This relates to the creation of larger steady aggregations and a subsequent decrease in the specific area of the clay particles. As stated earlier, a decrease in the treated soil PI suggests that the clay wettability decreased, which decreased the swelling percentage.

Researchers have reported that soil PI is a suitable index of the swelling behavior of the soil. A decrease in the PI reduced the swelling behavior [45]. The swelling pressure that was determined based on ASTM D-4546 [30], Test Method A, for the clay was $33 \mathrm{kPa}$, which then decreased to $25 \mathrm{kPa}$ after the stabilization of the clay with $0.75 \%$ LS. With a closer look at the swelling curve (Figure 5(a)), it can be seen that at the beginning of the test, the increase rate of swelling for the stabilized sample is lower than that for unstabilized one. Moreover, the time required to complete the primary swell of treated specimen is more than that of untreated one. According to the above reasons, it can be concluded that due to the LS-stabilization, soil permeability is reduced because of the formed bonds between soil particles and their aggregation. Chen et al. [17] reported the same conclusion for the LSstabilized sandy silt.

The effect of compaction moisture content and density on the swelling percentage of the untreated and LS-treated soils was examined, as depicted in Figure 6. An increase in the density of both of the untreated and LS-treated samples was found to be increasing the swelling percentage. In fact, increasing the density increases the number of soil particles in a given volume of the soil, which increased the specific area of the particles. The ability of water absorption and swelling per-

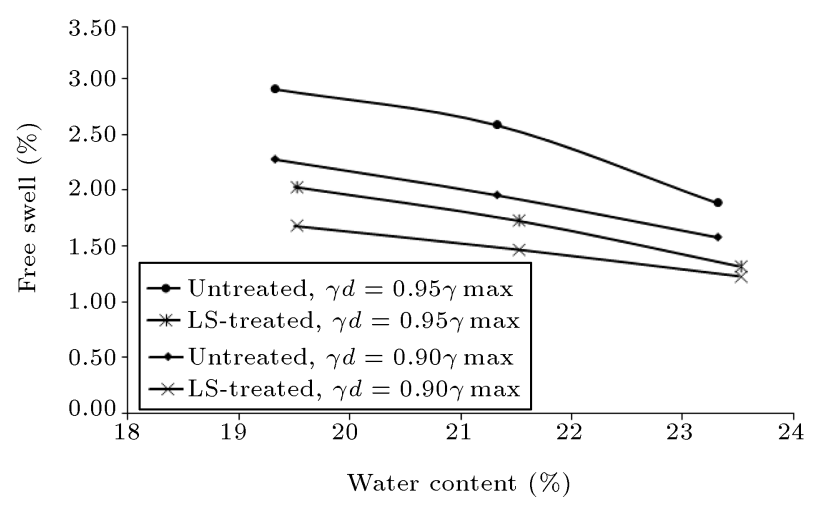

Figure 6. Effect of density and compaction moisture content on the swell percent of the treated and untreated soils.

centage of the sample also increased. However, for the treated sample, with the rising density, the rate of swell increase is lower than the untreated one. Increase in the initial sample moisture content decreased the swelling percentage of the samples. Swelling is the result of disturbance in the internal stress equilibrium of the soil particle by changes in moisture content [46]. Whenever the change in moisture content is greater, the greater change occurs in the internal stress balance of the soil particles and, thus, the swell increases [46]. Since the sample with a lower moisture content (dry side of the density curve) is different from that with saturation moisture content, changes in the moisture content of these samples are more than those in the samples with higher moisture content (wet side of the density curve). Therefore, changes in the internal stress balance of the soil particles of these samples will be greater whose swelling increases. In fact, a sample having a lower moisture content showed a greater ability to absorb water. Thus, many changes occurred in the sample moisture content and, thus, its swelling increased.

4.5. Effect of wet/dry cycles on swell behavior Swelling curves of the untreated and LS-treated specimens with $\mathrm{OMC}$ and $0.95 \mathrm{MDUW}$ for 0 to 4 cycles of

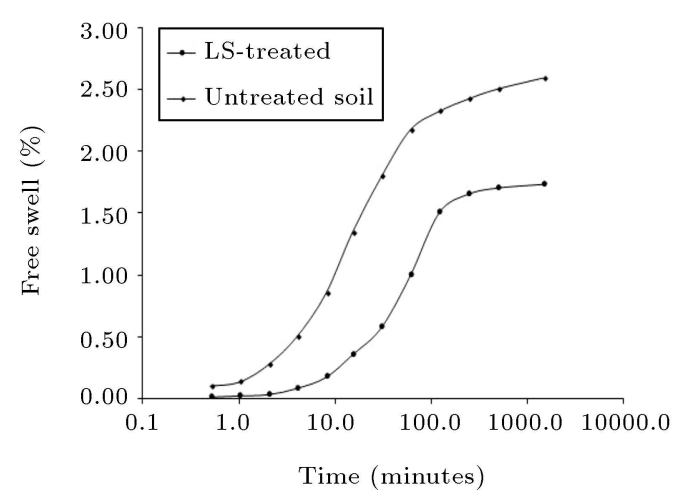

(a)

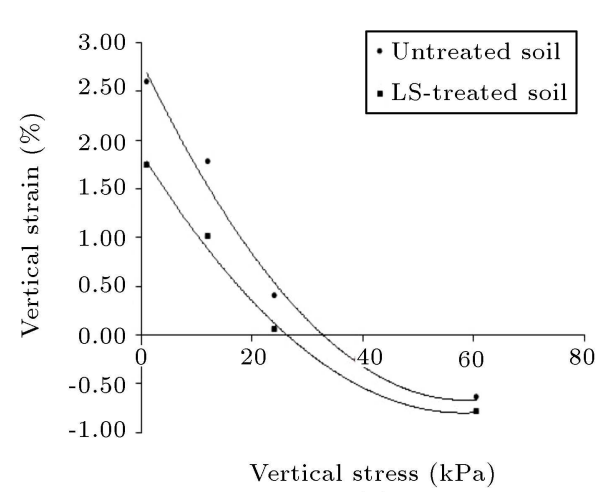

(b)

Figure 5. Effect of LS-treatment on (a) swell percent and (b) swell pressure of the expansive clay. 


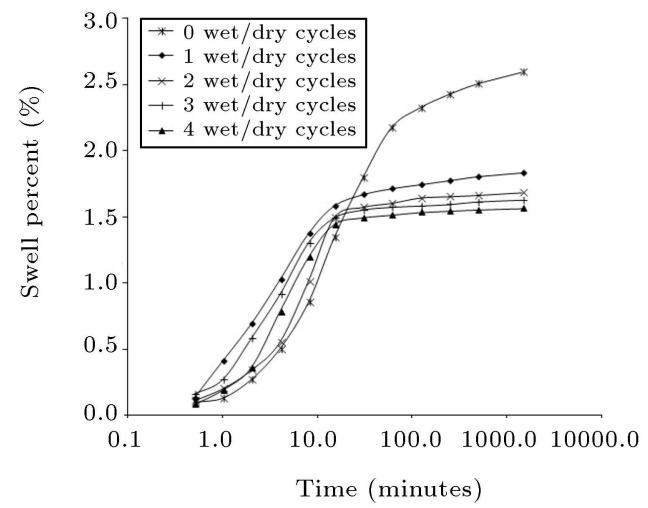

(a)

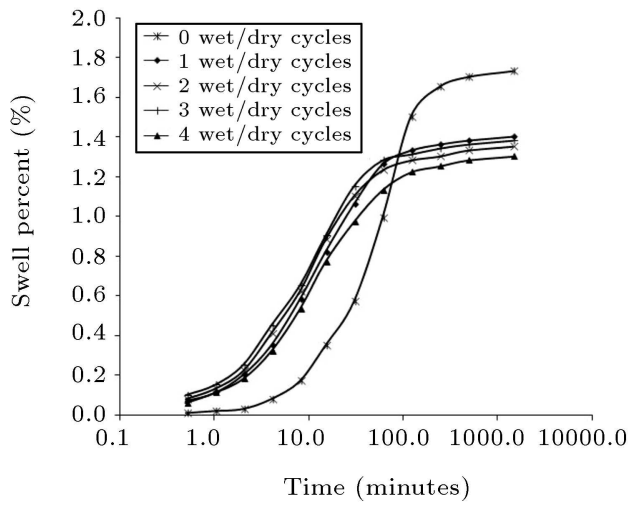

(b)

Figure 7. Swell curve of (a) untreated and (b) lignosulfonate-treated specimens for different wetting and drying cycles.

wetting and drying are shown in Figure 7. Based on this figure, the swelling percentage for both samples, at Cycle 0 , is significantly greater than the corresponding value at Cycle 4. In addition, a closer look at the curve data shows that both of the untreated and LS-treated samples at Cycles 1 to 4 require a shorter time (about 10 to 50 minutes for untreated and 50 to 100 minutes for LS-treated samples) to reach the maximum value of swell or the steady state of the primary swelling than the sample without wetting and drying cycles (more than 100 minutes for both of the untreated and LS-treated samples). In addition, for both stabilized and unstabilized samples at Cycles 1 to 4 of wetting and drying, the increase rate of swelling in the initial time periods is more than the corresponding value at Cycle 0 . These factors indicate that the soil samples at Cycles 1 to 4 have a more permeable structure than the soil sample at Cycle 0 [33]. This behavior of the untreated sample can be attributed to the aggregation of soil particles due to the wetting and drying cycles that cause greater permeability [33]. For the treated specimen, in addition to the previous reason, this behavior can be attributed to the gradual degradation of bonding materials between soil particles (LS polymer chains) because of wetting and drying cycles [47].

Figure 8 presents the swell percent of the untreated and LS-treated samples with wetting and drying cycles. Important findings from this figure include the following:

- Swelling percentage of specimens decreased with the increase of wetting and drying cycles. This decrease can be attributed to the continuous rearrangement of particles during the wetting and drying cycles that cause the lower orientation of structural members due to the aggregation of soil structure during the layering. Actually, due to this factor, the ability of water absorption is reduced and, thus, the swelling percentage decreases;

- For both of untreated and treated samples, the

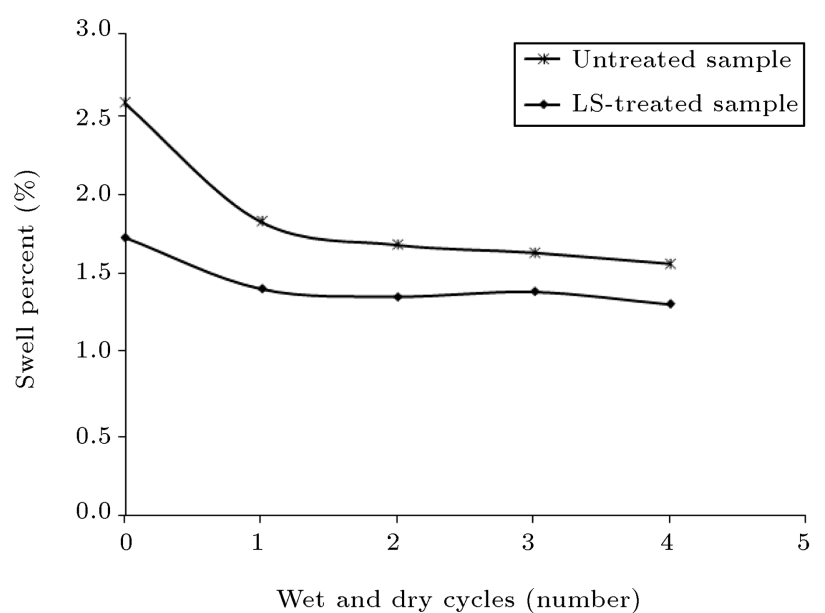

Figure 8. Effect of wetting and drying cycles on the swell percentage of the untreated and lignosulfonate-treated samples.

maximum decrease in swelling percentage occurs after Cycle 1 of wetting and drying. This means that the maximum change in soil structure (that stated above) occurs in Cycle 1 of wetting and drying;

- Decrease in the swelling percentage of the treated sample is lower than the untreated one. In this case, because of the existence of cementation between soil particles due to the stabilization, minor changes occurred in the soil structure;

- For the LS-treated sample, after 2 cycles of wetting and drying, the swelling percentage increased slightly in the third cycle and reduced again after this cycle. Initial decrease in the swelling percentage of the LS-treated sample resulted from the change of soil structure during the wetting and drying cycles. Due to the application of more cycles of wetting and drying, the bonds between the particles gradually decreased [47]. The increase of swelling percentage in the third cycle can be attributed to this gradual deterioration of chemical bonds. After this cycle, the 
LS-treated sample behaved similarly to untreated soil and the swelling percentage reduced again;

- Even though the swelling percentage decreased, it appears to have leveled off after about 3 to 4 cycles (equilibrium cycles).

These findings are consistent with the results reported by Chen [48], Difi and Bluemel [49], and AlHomoud et al. [33]. However, they are inconsistent with the noted observations by Osipove et al. [50] and Day [51]. A possible reason for this difference is that this research and those done by Chen [48], Difi and Bluemel [49], and Al-Homoud et al. [33] allowed the sample to dry into its initial moisture content (i.e., specimens allowed to partially shrink to about their initial height). On the other hand, in the studies of Osipov et al. [50] and Day [51], the soils were allowed to fully shrink well below their initial height to a much lower moisture content close to the shrinkage limit.

\subsection{Consolidation test}

Specimens in consolidation tests are compacted with 90 and $95 \%$ of MDUW. For the preparation of stabilized samples, the optimum percentage of LS $(0.75 \%$ LS by dry weight of the soil), determined by UCS and Atterberg limits tests, was used. The prepared specimens were cured for 28 days. Similar to the swell tests, the effects of compaction moisture content change and wet/dry cycles on consolidation characteristics of treated and untreated samples were investigated. In this research, coefficient of consolidation $\left(C_{V}\right)$ was calculated by means of Casagrande semi logarithmic method.

The consolidation test results under the influence of various factors are briefly shown in Table 5 . The values of the coefficient of consolidation shown in
Table 5 are the mean values of this coefficient at different rates of pressure.

\subsection{Effect of stabilization on the compression index $\left(C_{C}\right)$, swell index $\left(C_{s}\right)$, and coefficient of consolidation $\left(C_{V}\right)$}

Consolidation curves for the untreated and LS-treated specimens with OMC and 95\% MDUW are shown in Figure 9. According to this figure, for the untreated and treated samples, the compression index was equal to 0.203 and 0.157 , respectively, and the swell index was calculated as 0.0316 and 0.0248 , respectively, which is also shown in Table 5. In fact, due to the stabilization of expansive soil of Amol with LS, the compression and swell indices of the soil reduced. The reduction of these indices means that the settlement and swell of the stabilized sample are lower than those of the untreated one. Based on this reduction, it can be concluded that stabilization with LS improves the consolidation properties of the soil. This improvement in soil con-

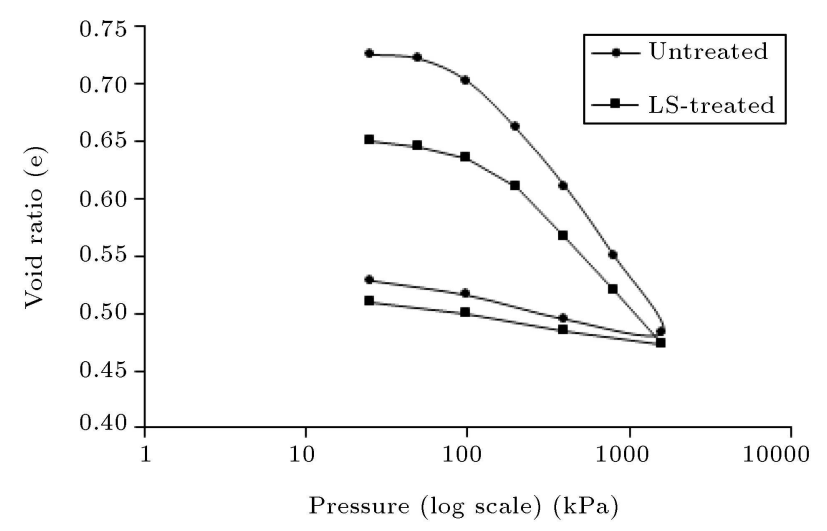

Figure 9. Consolidation curves for the untreated and lignosulfonate-treated samples with optimum moisture content and 95\% Maximum Dry Unit Weight (MDUW).

Table 5. Consolidation test results under the influence of various factors.

\begin{tabular}{|c|c|c|c|c|c|}
\hline Specimen & $\begin{array}{l}\text { Density } \\
(\%)\end{array}$ & $\begin{array}{c}\text { Moisture } \\
\text { content (\%) }\end{array}$ & $\begin{array}{l}\text { Compression } \\
\text { index }\end{array}$ & $\begin{array}{l}\text { Swell } \\
\text { index }\end{array}$ & $\begin{array}{l}\text { Coefficient of consolidation } \\
\qquad\left(\times 10^{-4} \mathrm{~cm}^{2} / \mathrm{s}\right)\end{array}$ \\
\hline \multirow{6}{*}{ Untreated } & 90 & 19.3 & 0.232 & 0.0286 & 10.06 \\
\hline & & 21.3 & 0.216 & 0.0251 & 8.95 \\
\hline & & 23.3 & 0.216 & 0.0246 & 8.82 \\
\hline & 95 & 19.3 & 0.229 & 0.0352 & 8.91 \\
\hline & & 21.3 & 0.203 & 0.0316 & 7.92 \\
\hline & & 23.3 & 0.199 & 0.0314 & 6.14 \\
\hline \multirow{6}{*}{ LS-treated } & 90 & 19.5 & 0.166 & 0.0199 & 7.3 \\
\hline & & 21.5 & 0.17 & 0.0211 & 7.16 \\
\hline & & 23.5 & 0.173 & 0.0221 & 6.08 \\
\hline & 95 & 19.5 & 0.153 & 0.0226 & 6.98 \\
\hline & & 21.5 & 0.157 & 0.0248 & 6.12 \\
\hline & & 23.5 & 0.162 & 0.0255 & 4.38 \\
\hline
\end{tabular}


solidation properties is the result of absorption of clay particles towards each other due to the neutralization of the negative charges of clay mineral surfaces by polymer chains of LS and the formation of stable masses within the pore spaces of the soil [15].

The coefficient of consolidation is related to the length of time to carry out a degree of consolidation [52]. This coefficient is determined by two factors: the amount of water that comes out and the speed at which water flows out. The lower coefficient of consolidation indicates less permeability. It can be seen from Table 5 that the coefficients of consolidation for the untreated and LS-treated samples with OMC and $95 \%$ MDUW are equal to $7.92 \times 10^{-4}$ and $6.12 \times 10^{-4} \mathrm{~cm}^{2} / \mathrm{s}$, respectively. In fact, due to the stabilization, the coefficient of consolidation reduced. A decrease in the amount of the coefficient of consolidation is the result of a change in the soil structure due to the formation of bonds between clay particles and polymer chains of LS. Since decreasing the amount of coefficient of consolidation indicates less soil permeability, it can be concluded that the soil permeability decreases due to stabilization with LS. Similar results have been reported by other researchers in this regard including Chen et al. [17] who demonstrated that the amount of permeability reduced for sandy silt due to the stabilization with LS.

\subsection{Effect of compaction moisture content and density change of specimen}

As can be seen from the Table 5, for untreated soil with $95 \%$ MDUW, the specimen with lower moisture content is characterized by greater compression and swell indices. In other words, the untreated specimen with lower moisture content has a steeper slope in the consolidation curve. With increasing specimen moisture contents, the slope of the curves is reduced.

In expansive soils, a significant change in moisture content indicates a higher degree of disturbance in the soil structure. However, the impact of disturbance on the consolidation characteristics of the expansive soil is not similar to that of non-expansive clay. In non-expansive soils, the soil that is subject to further disturbance shows a consolidation curve with a mild slop [46], while the laboratory results of the expansive soil of Amol show that the soil with greater moisture content change (greater swell) has a consolidation curve with a steeper slope.

Consolidation tests of the remolded specimens of expansive soil with different moisture contents and different densities led to a result that was different from the typical process in non-expansive soils. Tests on the prepared samples with the same density and different moisture contents showed different consolidation properties (different compression and swell indices). According to Table 5 and Figure 10, for the untreated

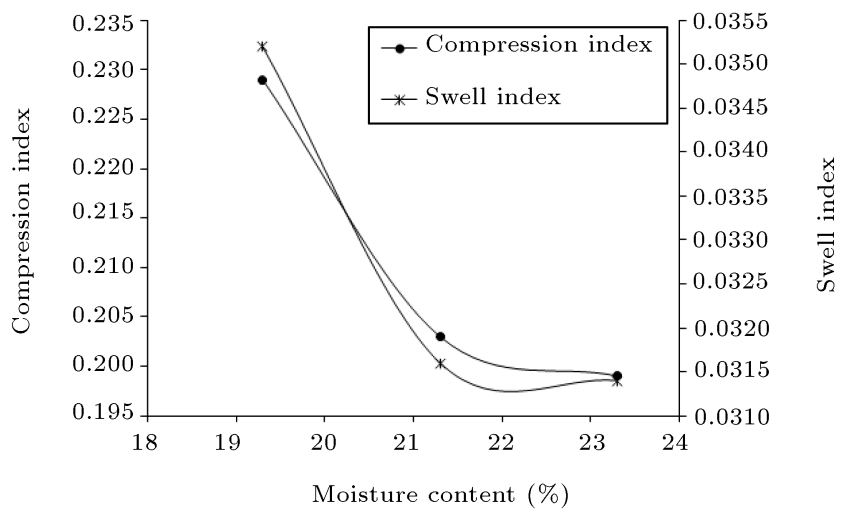

Figure 10. Variation of compression and swell indices for untreated specimens with different moisture contents at a density of $95 \%$.

soil with $95 \%$ MDUW and different moisture contents, the sample with a highly significant swelling capability (based on the swell test results, it was determined that the specimen with lower moisture content had a significant swelling capability) had greater compression and swell indices. For the untreated sample with a density rate of $90 \%$, the variation routines are the same. Similar results of Addis Ababa's expansive clay were reported by Mesfin [46].

According to Table 5, it is clear that for the untreated soil, with a decrease in density from $95 \%$ to $90 \%$ for specimens with the same moisture content of $21.3 \%$, the value of the compression index increased from 0.203 to 0.216 and the swell index reduced from 0.0316 to 0.0251 . Actually, with a decrease in density, the compression index of the soil showed a behavior similar to that of non-expansive soil and increased consequently. In other words, its settlement increased as a result of reduced density. In fact, the effect of density decrease by loosening the soil structure on the compression index is far more than that of reducing swell on the above parameter. The swell index of the soil reduced due to the density decrease, which is in agreement with the results of swell tests.

The effect of moisture content and density change on the coefficient of consolidation of the untreated soil is shown in Figure 11. Based on this figure, for specimens with the same density, the sample with lower moisture content has a greater coefficient of consolidation and with the increase of moisture content, the coefficient of consolidation reduces.

The sample compacted on the dry side of compaction curve has a flocculent structure, and one of the characteristics of this soil structure is its higher permeability coefficient than the sample compacted on the wet side of the compaction curve, which has a dispersed structure [52]. Since the coefficient of consolidation of soil is related to its permeability, the sample compacted with lower moisture content (dry 


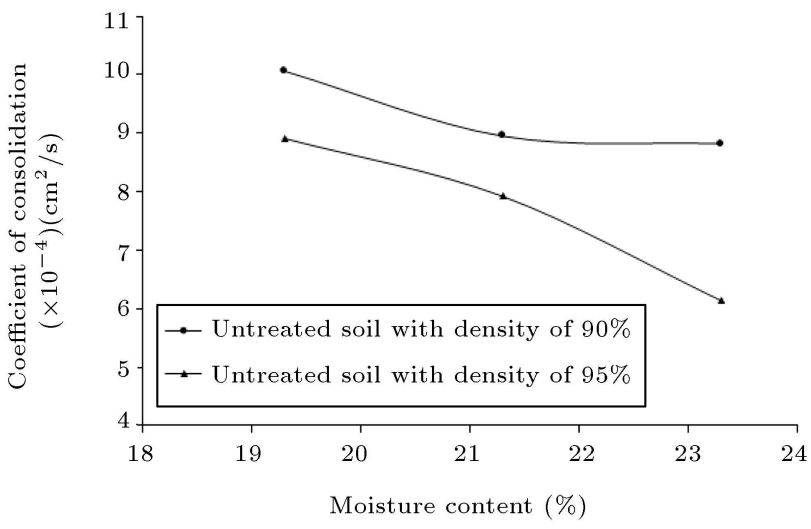

Figure 11. The effect of compaction moisture content on the coefficient of consolidation of untreated soil at densities of 90 and $95 \%$.

side of the compaction curve) has a greater coefficient of consolidation than the sample compacted with the same density and higher moisture content.

Further, from Figure 11, it can be observed that, for the same moisture content, the specimen with lower density has a greater coefficient of consolidation. In other words, with the increase of soil density, the distance between the soil particles decreases and the cavities or spaces that water can flow reduce, which in turn reduces permeability and, consequently, deceases the soil coefficient of consolidation.

The effect of compaction moisture content of the sample on the consolidation behavior of a stabilized soil has a different trend than the untreated soil. According to Table 5, for the LS-treated soil with density of $95 \%$ and different moisture contents, it can be seen that the compression and swell indices increase with increasing moisture content. Actually, the capability of the volume change of the soil increases. The reason for this distinct behavior of the treated soil, as compared to the untreated one, can be attributed to this factor that because of stabilization of expansive soil with LS, as stated in the Atterberg limits section, the soil expansivity changes from highly to moderate. Thus, the behavior of this stabilized soil will differ from the expansive soil, and this soil will show a behavior like a non-expansive soil.

The variations of compression and swell indices for the LS-treated specimens with the same moisture content and different densities are shown in Figure 12. With the decrease of density, as stated before, due to the loosening of the soil texture and the greater distance between particles, the soil compressibility and swell increase and decrease, respectively. For this reason, with decreasing density, the compression index of the soil increased and its swell index decreased.

The trend of variations of coefficient of consolidation for the LS-treated soil with changes in compaction moisture content and density is similar to that in the

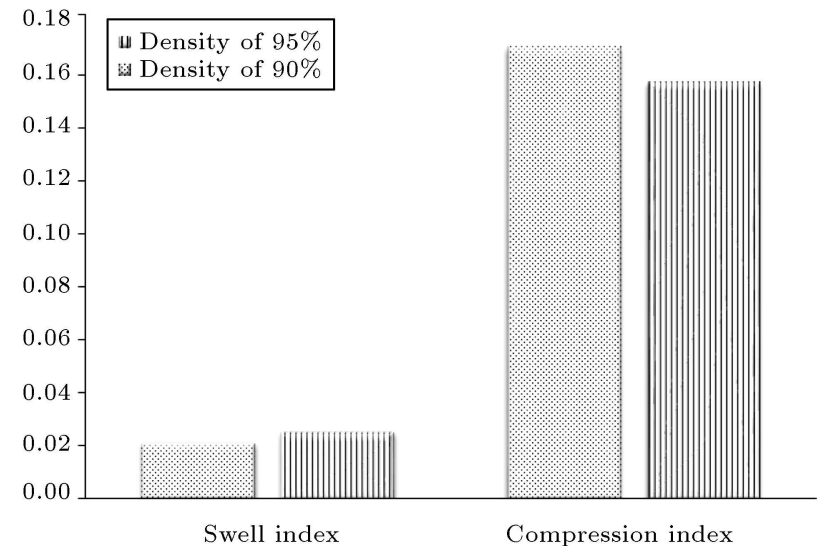

Figure 12. The variation of compression and swell indices of lignosulfonate-treated soil at the same moisture content $(21.5 \%)$ and different densities of 90 and $95 \%$.

untreated one. Generally, the consolidation coefficients of the treated samples are lower than those of the untreated samples due to the lower permeability of the stabilized specimen.

\subsection{Effect of wet/dry cycles on the consolidation parameters}

The variations of compression and swell indices of the untreated and treated samples with density of $95 \%$ and OMC under the influence of different wetting and drying cycles are shown in Figure 13 . With respect to this figure, it can be seen that by increasing the number of wetting and drying cycles, the compression index of the untreated sample increases. This increase can be attributed to the continuous rearrangement of particles during the wetting and drying cycles that leads to separating particles from each other in the soil structure, hence reducing its density [33]. In fact, due to this factor, the volume of empty voids in the soil structure increases and, as a result, the compression index increases. Moreover, according to this figure, it is clear that the maximum increase of the compression index occurred after one cycle of wetting and drying; after this cycle, the increase rate of the compression index reduced. Actually, the maximum number of changes in the soil structure as a result of wetting and drying occurred after one cycle of wetting and drying.

The swell index of the untreated sample (Figure 13(a)) was reduced by the increase of one cycle of wetting and drying. As stated above, because of wetting and drying cycles, the density of sample reduced. As indicated in the section of swell tests, diminishing the sample density reduced its swelling. Similar to changes in the compression index, the maximum decrease in the swell index occurred during the first cycle of wetting and drying and, then, decreased with a slight slope.

The compression index of the LS-treated specimen (Figure 13(b)) increased with the increase of wetting and drying cycles. The reason for this increase 


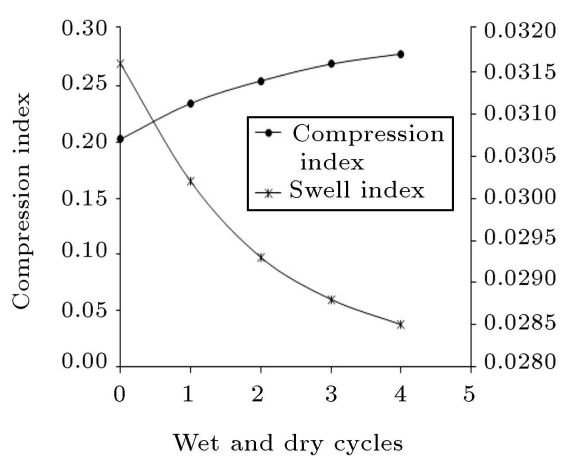

(a)

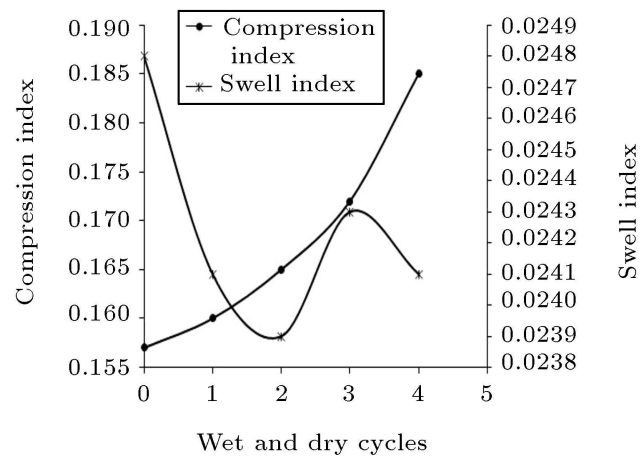

(b)

Figure 13. The effect of wetting and drying cycles on the compression and swell indices of (a) untreated and (b) LS-treated samples at optimum moisture content and density of $95 \%$.

is similar to the untreated one that is attributed to the change of soil structure during the wetting and drying cycles. The difference between curves of the compression index of the untreated and LS-treated samples shown in Figure 13 is that, at the untreated curve, the direction of concavity is downward, while, at the curve of LS-treated specimen, the direction of concavity is upward. This means that at the untreated curve, the increase rate of the compression index is reduced by the increase of wetting and drying cycles, the reason for which was stated above. However, at the LS-treated curve, the increase rate of the compression index increased with an increase in the wetting and drying cycles. This behavior can be attributed to the gradual deterioration of the stabilizing agent (LS) during the wetting and drying cycles. In fact, with the release of the stabilizing agent, the bonds between the soil particles was lost and the change in the soil structure increased.

The swell index variations of the LS-treated sample because of wetting and drying cycles also are shown in Figure 13(b). The swell index of the LS-treated specimen decreased until the 2nd cycle of wetting and drying. The reason for this reduction is the same as the case of the untreated sample. After 3 cycles of wetting and drying, the variation trend of the swell index reversed and increased. As stated above, during the wetting and drying cycles, the stabilizing agent gradually deteriorated. Thus, after the 3 cycles, the maximum release of the stabilizing agent may occur and the sample could behave like the untreated specimen. In the section of the swell tests, it was determined that the swell percentage of the LS-treated sample was lower than that of the untreated one. Actually, following the three aforementioned cycles, the stabilized sample was converted into the untreated sample; thus, the swell index increase can be attributed to this factor. At Cycle 4 of wetting and drying, again, the swell index reduced. Actually, in this step, the sample behaved like the untreated specimen and its structure changed, leading to a reduction in the density and swell index of the specimen.

\subsection{Effect on microstructure}

The $4000 \times$ SEM images of the untreated and LStreated clays were used to examine the effect of LS (Figure 14). The structure of the untreated clay is discontinuous, flaky and without aggregations. Pores are visible due to the lack of cementation between particles. The SEM image of the stabilized soil with optimum content of LS and 28-day curing time revealed important changes in the structure. It changed with the progress of the electrostatic reaction between the clay and mixture of water-LS, revealing the subsequent formation of steady aggregation. Stabilization altered the untreated soil structure from a particle base to an aggregated structure with larger, yet fewer, inter-aggregate voids. The formation of larger interaggregate pores decreased the number and volume of inter-aggregate pores; thus, the penetration of water into the soil structure was limited and the swelling percentage reduced [14].

\section{Conclusion}

In this research, the effect of lignosulfonate (LS) on the volume change behavior of expansive soil was investigated. The most important results can be summarized as follows:

1. With the addition of LS, the Plastic Limit (PL) of the soil did not change considerably and remained almost constant, whereas Liquid Limit (LL) of the soil decreased significantly from $55 \%$ to $39 \%$. This significantly decreased $(15 \%)$ the Plasticity Index (PI) of the soil (from $29 \%$ to $14 \%$ ) with the addition of $0.75 \%$. This decrease in the PI of the soil altered the category of the soil from highly expansive to intermediate. However, an increase in the LSpercentage to above $0.75 \%$ adversely affected the soil properties; 

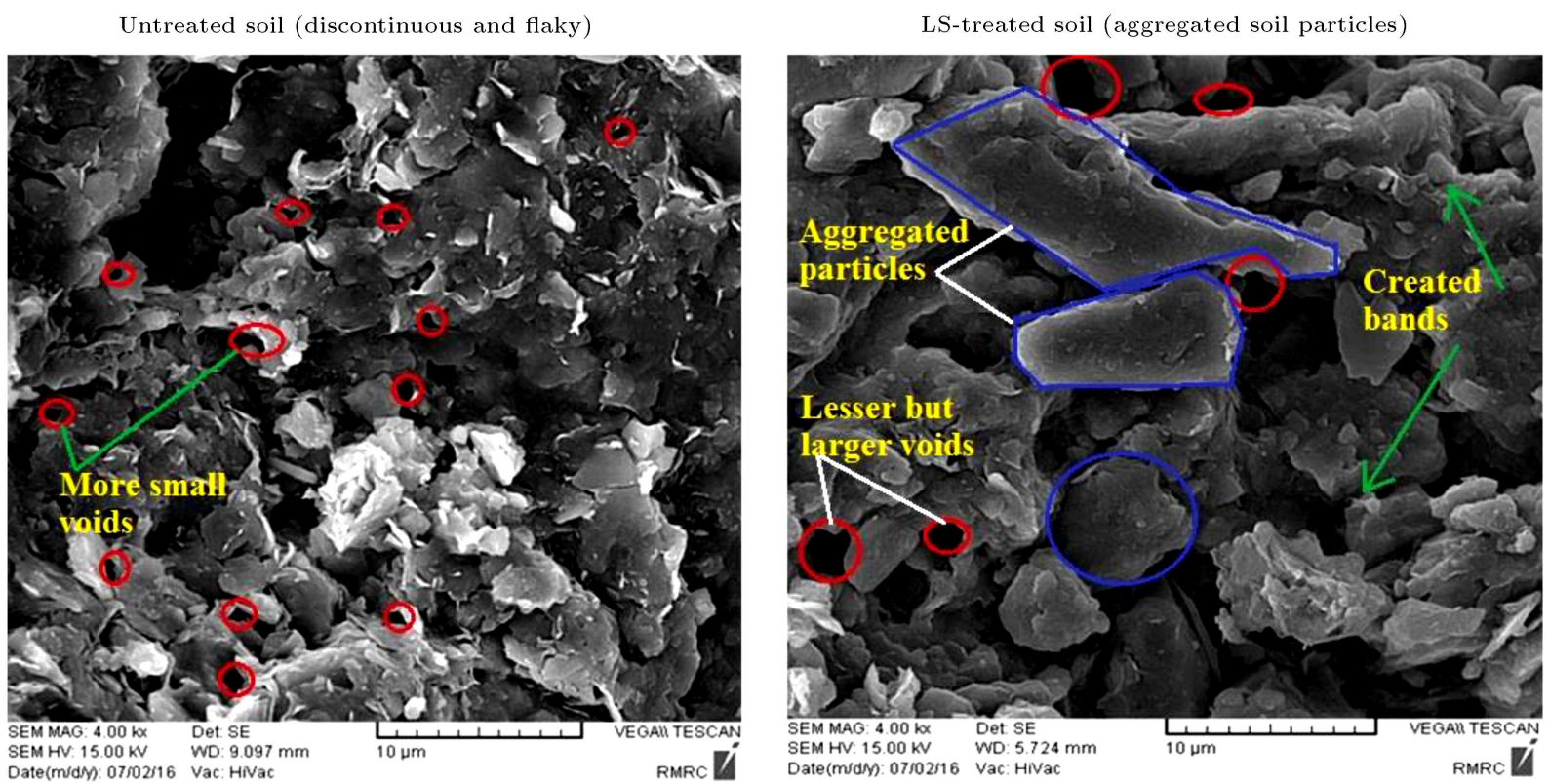

Figure 14. Microscopic image of the untreated and lignosulfonate-treated expansive clays with $4000 \times$ magnification.

2. With the treatment of the soil with $0.75 \%$ of LS, the swelling percentage and pressure of the clay reduced from $2.59 \%$ to $1.73 \%$ and from $33 \mathrm{kPa}$ to $25 \mathrm{kPa}$, respectively. A decrease in the stabilized soil PI suggests that the soil wettability decreased, causing a decrease in the swelling percentage;

3. By the stabilization of this expansive clay with LS, its compression index, swell index, and coefficient of consolidation reduced from $0.203,0.0316$, and $7.92 \times 10^{-4}$ to $0.157,0.0248$, and $6.12 \times 10^{-4} \mathrm{~cm}^{2} / \mathrm{s}$, respectively;

4. The effect of wetting and drying cycles on the swell and consolidation characteristics of the untreated soil was highly clear at the 1 st cycle of wetting and drying. Following this cycle, its effect gradually decreased. However, in the treated specimens, at the beginning cycles of wetting and drying, its effect on the soil properties was low and the rate of its effect increased by increasing the cycle number;

5. The effect of compaction moisture content of the sample on the consolidation behavior of a stabilized soil had a different trend from the untreated soil. The compression and swelling indices increased with an increase in the moisture content for the LS-treated sample due to the alteration of the soil expansivity from highly to moderate, whereas these parameters changed adversely for the untreated one;

6. The Scanning Electron Microscope (SEM) micrographs showed that the untreated specimen structure was discontinuous, flaky and without aggre- gations. The lack of cementation between the particles increased the number of pores observed.

\section{Acknowledgements}

The authors acknowledge the funding support of Babol Noshirvani University of Technology through grant program NO. BNUT/370273/97 and NO. BNUT/925140010/93.

\section{References}

1. Basma, A.A., Al-Homoud, A.S., and Husein, A. "Laboratory assessment of swelling pressure of expansive soils", Applied Clay Science, 9(5), pp. 355-368 (1995).

2. Al-Mukhtar, M., Lasledj, A., and Alcover, J.F. "Behaviour and mineralogy changes in lime-treated expansive soil at 20 C", Applied Clay Science, 50(2), pp. 191-198 (2010).

3. Al-Rawas, A.A., Hago, A.W., and Al-Sarmi, H. "Effect of lime, cement and Sarooj (artificial pozzolan) on the swelling potential of an expansive soil from Oman", Building and Environment, 40(5), pp. 681-687 (2005).

4. Chen, F.H., Foundations on Expansive Soils, 12, Elsevier, Netherlands (2012).

5. Dafalla, M.A. and Shamrani, M.A. "Road damage due to expansive soils: Survey of the phenomenon and measures for improvement", In Design, Construction, Rehabilitation, and Maintenance of Bridges, pp. 73-80 (2011).

6. Nelson, J. and Miller, D.J., Expansive Soils: Problems and Practice in Foundation and Pavement Engineering, John Wiley \& Sons, New York (1997). 
7. Khemissa, M. and Mahamedi, A. "Cement and lime mixture stabilization of an expansive overconsolidated clay", Applied Clay Science, 95, pp. 104-110 (2014).

8. Harichane, K., Ghrici, M., Kenai, S., and Grine, K. "Use of natural pozzolana and lime for stabilization of cohesive soils", Geotechnical and Geological Engineering, 29(5), pp. 759-769 (2011).

9. Indraratna, B. "Utilization of lime, slag and fly ash for improvement of a colluvial soil in New South Wales, Australia", Geotechnical and Geological Engineering, 14(3), pp. 169-191 (1996).

10. Mahamedi, A. and Khemissa, M. "Cement stabilization of compacted expansive clay", Online J. Sci. Technol, 3(1), pp. 33-38 (2013).

11. Miura, N., Horpibulsuk, S., and Nagaraj, T.S. "Engineering behavior of cement stabilized clay at high moisture content", Soils and Foundations, 41(5), pp. 33-45 (2001).

12. Mohamedzein, Y.E. and Al-Rawas, A.A. "Cementstabilization of sabkha soils from al-auzayba, sultanate of Oman", Geotechnical and Geological Engineering, 29(6), p. 999 (2011).

13. Sharma, N.K., Swain, S.K., and Sahoo, U.C. "Stabilization of a clayey soil with fly ash and lime: a micro level investigation", Geotechnical and Geological Engineering, 30(5), pp. 1197-1205 (2012).

14. Alazigha, D.P., Indraratna, B., Vinod, J.S., and Ezeajugh, L.E. "The swelling behaviour of lignosulfonatetreated expansive soil", Proceedings of the Institution of Civil Engineers-Ground Improvement, 27, pp. 1-12 (2016).

15. Chen, Q. and Indraratna, B. "Deformation behavior of lignosulfonate-treated sandy silt under cyclic loading", Journal of Geotechnical and Geoenvironmental Engineering, 141(1), 06014015 (2014).

16. Chen, Q. and Indraratna, B. "Shear behaviour of sandy silt treated with lignosulfonate", Canadian Geotechnical Journal, 52(8), pp. 1180-1185 (2014).

17. Chen, Q., Indraratna, B., Carter, J., and Rujikiatkamjorn, C. "A theoretical and experimental study on the behaviour of lignosulfonate-treated sandy silt", Computers and Geotechnics, 61, pp. 316-327 (2014).

18. Chen, Q., Indraratna, B., and Rujikiatkamjorn, C. "Behaviour of lignosulfonate-treated soil under cyclic loading", Proceedings of the Institution of Civil Engineers-Ground Improvement, 169(2), pp. 109-119 (2015).

19. Puppala, A.J. and Hanchanloet, S. "Evaluation of a new chemical treatment method on strength and resilient properties of a cohesive soil", Transportation Research Board, Paper No, 990389 (1999).

20. Tingle, J. and Santoni, R. "Stabilization of clay soils with nontraditional additives", Transportation Research Record: Journal of the Transportation Research Board, 1819, pp. 72-84 (2003).
21. Vinod, J.S., Indraratna, B., and Al Mahamud, M.A. "Stabilization of an erodible soil using a chemical admixture", Proceeding of the ICE - Ground Improvement, 163(1), pp. 43-51 (2010).

22. Alazigha, D.P., Indraratna, B., Vinod, J.S., and Heitor, A. "Mechanisms of stabilization of expansive soil with lignosulfonate admixture", Transportation Geotechnics, 14, pp. 81-92 (2018).

23. Ta'negonbadi, B. and Noorzad, R. "Stabilization of clayey soil using lignosulfonate", Transportation Geotechnics, 12, pp. 45-55 (2017).

24. ASTM D-698, Standard Test Methods for Laboratory Compaction Characteristics of Soil Using Standard Effort, Annual Book of ASTM Standards, USA (2012).

25. ASTM D-4609, Standard Guide for Evaluating Effectiveness of Admixtures for Soil Stabilization, Annual Book of ASTM Standards, USA (2008).

26. Consoli, N.C., Rosa, A.D., and Saldanha, R.B. "Variables governing strength of compacted soil-fly ash-lime mixtures", Journal of Materials in Civil Engineering, 23(4), pp. 432-440 (2010).

27. Wang, B.T., Zhang, C.H., Qiu, X.L., Ji, E.Y., and Zhang, W.H. "Research on wetting-drying cycles' effect on the physical and mechanical properties of expansive soil improved by OTAC-KCl", Advances in Materials Science and Engineering, 2015, Article ID 304276, 7 pages (2015).

28. ASTM D-2166, Standard Test Method for Unconfined Compressive Strength of Cohesive Soil, Annual Book of ASTM Standards, USA (2013).

29. Osinubi, K.J. and Nwaiwu, C.M. "Compaction delay effects on properties of lime-treated soil", Journal of Materials in Civil Engineering, 18(2), pp. 250-258 (2006).

30. Pourakbar, S., Asadi, A., Huat, B.B., and Fasihnikoutalab, M.H. "Stabilization of clayey soil using ultrafine palm oil fuel ash (POFA) and cement", Transportation Geotechnics, 3, pp. 24-35 (2015).

31. ASTM D-4546, Standard Test Methods for OneDimensional Swell or Collapse of Soils, Annual Book of ASTM Standards, USA (2014).

32. ASTM D-2435, Standard Test Methods for OneDimensional Consolidation Properties of Soils Using Incremental Loading, Annual Book of ASTM Standards, USA (2011).

33. Al-Homoud, A.S., Basma, A.A., Husein Malkawi, A.I., and Al Bashabsheh, M.A. "Cyclic swelling behavior of clays", Journal of Geotechnical Engineering, 121(7), pp. 562-565 (1995).

34. ASTM D-422, Standard Test Method for Particle-Size Analysis of Soils, Annual Book of ASTM Standards, USA (2007).

35. ASTM D-2487, Standard Practice for Classification of Soils for Engineering Purposes (Unified Soil Classification System), Annual Book of ASTM Standards, USA (2011). 
36. Holtz, W.G. and Gibbs, H.J. "Engineering properties of expansive clays", Transactions of the American Society of Civil Engineers, 121(1), pp. 641-663 (1956).

37. ASTM D-854, Standard Test Methods for Specific Gravity of Soil Solids by Water Pycnometer, Annual Book of ASTM Standards, USA (2014).

38. ASTM E-1621, Standard Guide for Elemental Analysis by Wavelength Dispersive X-Ray Fluorescence Spectrometry, Annual Book of ASTM Standards, USA (2013).

39. ASTM E-1252, Standard Practice for General Techniques for Obtaining Infrared Spectra for Qualitative Analysis, Annual Book of ASTM Standards, USA (2013).

40. Coates, J. "Interpretation of infrared spectra, a practical approach", Encyclopedia of Analytical Chemistry, Wiley (2000).

41. Boeriu, C.G., Bravo, D., Gosselink, R.J., and van Dam, J.E. "Characterisation of structure-dependent functional properties of lignin with infrared spectroscopy", Industrial Crops and Products, 20(2), pp. 205-218 (2004)

42. Hergert, H.L. "Infrared spectra of lignin and related compounds. II. Conifer lignin and model compounds 1, 2", The Journal of Organic Chemistry, 25(3), pp. 405-413 (1960).

43. Jacox, M.E. "Vibrational and electronic energy levels of polyatomic transient molecules. Supplement B", Journal of Physical and Chemical Reference Data, 32(1), pp. 1-441 (2003).

44. Rao, C.N.R., Venkataraghavan, R., and Kasturi, T.R. "Contribution to the infrared spectra of organosulphur compounds", Canadian Journal of Chemistry, 42(1), pp. 36-42 (1964).

45. Saride, S., Puppala, A.J., and Chikyala, S.R. "Swellshrink and strength behaviors of lime and cement stabilized expansive organic clays", Applied Clay Science, 85, pp. 39-45 (2013).

46. Mesfin, K., Relationship between Consolidation and Swelling Characteristics of Expansive Soils of Addis Ababa Ph.D. Dissertation, Addis Ababa University, (2005).

47. Park, S.S. "Effect of wetting on unconfined compressive strength of cemented sands", Journal of Geotechnical and Geoenvironmental Engineering, 136(12), pp. 1713-1720 (2010).
48. Chen, F.H. "The use of piers to prevent uplifting of lightly loaded structures founded on expansive soils", In Proceeding of International Research and Engineering Conference on Expansive Clay Soils, Texas (1965).

49. Dif, A.E. and Bluemel, W.F. "Expansive soils under cyclic drying and wetting", Geotechnical Testing Journal, 14(1), pp. 96-102 (1991).

50. Osipov, V.I., Bik, N.N., and Rumjantseva, N.A. "Cyclic swelling of clays", Applied Clay Science, 2(4), pp. 363-374 (1987).

51. Day, R.W. "Swell-shrink behavior of compacted clay", Journal of Geotechnical Engineering, 120(3), pp. 618623 (1994).

52. Das, B.M., Advanced Soil Mechanics, 3rd Ed., Taylor \& Francis, New York (2008).

\section{Biographies}

Reza Noorzad was born in Nour, Mazandaran, Iran in 1964. He received both his BSc and MSc degrees in Civil Engineering and Geotechnical Engineering from Tehran University, Tehran, Iran in 1990 and 1994, respectively; He obtained his $\mathrm{PhD}$ degree in Geotechnical Engineering from Sharif University of Technology, Tehran, Iran in 2000. He is currently an Associate Professor at the Department of Civil Engineering at Babol Noshirvani University of Technology. From 2004 to 2007, he was the Head of Central Library and Documentation Centre at Mazandaran University. His research interests include soil improvement, reinforced soil, earth dams, marine geotechnics, and geotechnical earthquake engineering.

Bahram Ta'negonbadi was born in Gonbad, Iran in 1989. He received the BSc degree in Civil Engineering from Ferdowsi University of Mashhad in 2011 and MSc degree in Geotechnical Engineering from Sharif University of Technology in 2013. He is currently a PhD student in Geotechnical Engineering at the Babol Noshirvani University of Technology. His main areas of research interest are soil improvement, underground spaces (tunnels) under dynamic loadings, soil-structure interaction, earth dams, and geotechnical earthquake engineering. 